\title{
Prevalence and characterization of Staphylococcus aureus from raw milk in Mumbai region
}

\author{
V. R. Patange ${ }^{1}$, V. D. Thorat ${ }^{1 *}$, S. B. Majee ${ }^{1}$ and R. S. Gandge ${ }^{1}$ \\ ${ }^{1}$ Department of Veterinary Microbiology, Mumbai Veterinary College, Maharashtra Animal and \\ Fishery Sciences University, Nagpur - 440 001, Maharashtra, India
}

\begin{abstract}
Staphylococcus aureus is a vital pathogenic microorganism and can cause spoilage and contamination of milk samples that make it unsafe for drinking purposes. Such contaminated milk causes many infections in the human population like gastroenteritis, diarrhea, nausea, abdominal cramps and fever. The present study was planned to isolate and identify $S$. aureus from raw milk samples collected from the Mumbai region. A total of 106 raw milk samples were collected from cattle and buffalo during this study. These samples were processed for isolation and identification of $S$. aureus by conventional method and molecular characterization by PCR assay. Based on conventional method results, 45 isolates were identified as Staphylococcus aureus. The isolation rate of Staphylococcus aureus from raw milk of cattle and buffalo was found to be $\mathbf{4 2 . 4 5 \%}$ per cent. Antibiotic sensitivity testing of Staphylococcus aureus showed that imipenem was the most sensitive $(100 \%)$ antibiotic followed by amoxicllin/ clavulanic acid $(91.11 \%)$, ceftriaxone $(84.44 \%)$, tetracycline $(\mathbf{8 0} \%)$, ciprofloxacin $(\mathbf{7 7 . 7 7 \%})$ and amikacin $(\mathbf{7 1 . 1 1 \%})$. The most resistant antibiotics against Staphylococcus aureus were amikacin $(28.88 \%)$ followed by ciprofloxacin $(22.22 \%)$, tetracycline $(20 \%)$, ceftriaxone $(15.55 \%)$ and amoxycillin/ clavulanic acid $(\mathbf{8 . 8 8 \%})$. All the 45 isolates showed $N u c$ gene specific amplicon of $270 \mathrm{bp}$. The present study poses a risk to the milk consumers as the raw milk samples contain $S$. aureus; therefore avoiding consumption of raw milk is the best alternative to remain safe from gastrointestinal infections.
\end{abstract}

Key words: Nuc PCR assay, Raw milk, Staphylococcus aureus

\section{Highlights}

- The isolation rate of Staphylococcus aureus from raw milk of cattle and buffalo was found to be $42.45 \%$.

- Antibiotic sensitivity testing of Staphylococcus aureus showed that imipenem is the most sensitive $(100 \%)$ antibiotic followed by amoxicllin/ clavulanic acid $(91.11 \%)$, ceftriaxone $(84.44 \%)$, tetracycline $(80 \%)$, ciprofloxacin $(77.77 \%)$ and amikacin $(71.11 \%)$.

- The most resistant antibiotics against Staphylococcus aureus are amikacin (28.88\%) followed by ciprofloxacin $(22.22 \%)$, tetracycline $(20 \%)$, ceftriaxone $(15.55 \%)$ and amoxycillin/ clavulanic acid $(8.88 \%)$.

- Avoiding consumption of raw milk is the best alternative to remain safe from gastrointestinal infections.

- Nuc PCR has successfully amplified the 270 bp product indicating the Staphylococcus aureus.

\section{INTRODUCTION}

Milk is considered as complete food. Dairy foods are ideal foods for all age groups in both rural and urban people all around the world as these are rich sources of protein, vitamins and minerals which are essential for health of human body. At present, India ranks first in world in

terms of milk production with $16 \%$ of global production (FAO, 2014).

The milk samples serve as an excellent source of many pathogenic microorganisms that may cause illness to the human population. Hence such raw contaminated milk samples, if

"Corresponding Author, E Mail: drvarshamicro@ gmail.com 
consumed by humans, may increase the risk of infections. So the quality of milk samples must be checked by microbiological analysis of milk before its consumption. Also all the hygienic precautions must be followed while collecting, processing and transporting milk samples from farm to the door of consumers (Soomro et al., 2002).

Raw milk may be contaminated by pathogenic microorganisms including, Staphylococcus aureus, Streptococcus spp., Escherichia coli, Bacillus spp., Brucella spp., Salmonella spp., yeasts and moulds. Staphylococcus aureus is the most common bacterial pathogen that causes contamination of raw milk samples, affecting the quality of milk samples. S. aureus is a facultative anaerobic gram-positive coccus, non-motile, catalase and coagulase positive bacteria found in water, dust and air. If such milk samples contaminated with Staphylococcus aureus are consumed by humans may cause severe gastrointestinal infections. Hence hygienic conditions at the farm level are an important factor of milk contamination. If milk handlers are not followed proper sanitary conditions at the farm level may cause $S$. aureus infection. Milk handlers must avoid coughing, sneezing while collecting milk or handling infected cows while milking healthy ones to prevent infections (Kadariya et al., 2014; Abebe et al., 2016).

$S$. aureus produces several toxins i.e haemolysin, leukotoxins, enterotoxins, exfoliative toxins, toxic shock syndrome toxins. Apart from that many enzymes and surface proteins are produced by $S$. aureus like coagulase, thermonuclease etc. These toxins when consumed by humans may cause severe gastrointestinal infections like nausea, vomiting, diarrhea, abdominal pain and toxic shock syndrome etc. Coagulase, enzyme produced by $S$. aureus is used as marker for the bacteria. The Nuc gene, which encodes the thermostable nuclease of Staphylococcus, is used for the identification of $S$. aureus isolates in many laboratories (Lachica et al., 1971; Tucker, et al., 1978; Kerouanton et al., 2007; Fagundes et al., 2010).
The quality of raw milk samples can be improved by adopting proper hygienic practices. The milking of animals must be done in a clean area free from dust and mud. The healthy and infected animals must be kept separately. The infected animals should not be mixed with healthy ones during the milking procedure. The milker should wash hands with soap and clean water before milking. The milker should wash the udder with clean and warm water, dry the udder with clean cloth, and use clean containers for milking. The milker should not cough or sneeze during milking. Also, milking of infected cows should be done separately, their milk should be discarded, and teat dip must be carried out to reduce the chances of contamination of raw milk samples (De Silva, 2016). The present study was planned to isolate and identify $S$. aureus from raw milk samples collected from the Mumbai region and detect S. aureus by Nuc PCR assay.

\section{MATERIALS AND METHODS}

A total of 106 raw milk samples of cattle and buffalo were collected from the Mumbai region during the present study, as shown in Table 1. The samples were transported to the laboratory in iceboxes and stored at $4^{\circ} \mathrm{C}$ till further processing. All samples were processed for isolation and identification of Staphylococcus spp. by conventional methods within $2 \mathrm{hrs}$ of arrival in the laboratory and further subjected to PCR.

\section{Isolation and identification of Staphylococcus} spp.

Isolation: The milk samples were processed for isolation of Staphylococcus spp. using standard bacteriological procedures (OIE, 2004). The milk samples were centrifuged at $12000 \mathrm{rpm}$ for 15 minutes and pellet was inoculated aseptically on the plates of nutrient Agar and Mannitol salt agar, and incubated at $37^{\circ} \mathrm{C}$ for $24 \mathrm{hrs}$ in incubator. The cultures were observed regularly for the appearance of growth. The colonies suggestive of Staphylococcus spp. were checked for the morphology and direct microscopy by Gram's staining method. The 
Table 1. Details of specimens collected from different sources

\begin{tabular}{cllc}
\hline S1.No & \multicolumn{1}{c}{ Name of the farm } & Species & $\begin{array}{c}\text { Number of milk samples } \\
\text { collected for isolation }\end{array}$ \\
\hline 1 & Narayan Dairy Farm, Dombivli & Cow & 1 \\
2 & Durga Dairy Farm, Dombivli & Cow & 1 \\
3 & Nanda Dairy, Dombivli & Cow & 1 \\
4 & Yadav Dairy, Dombivli & Cow & 1 \\
5 & Goshala, Dombivli & Cow & 5 \\
6 & Kopargaon Dairy Farm & Cow & 10 \\
7 & Ambernath Dairy Farm & Buffalo & 20 \\
8 & Shubham Dairy Farm, Diva & Cow & 5 \\
9 & Shri Radha Govind Goshala, Badlapur & Cow & 5 \\
10 & Goshala Kalwa & Cow & 5 \\
11 & Local vendor, Ambernath & Buffalo & 7 \\
12 & Thane Dairy Farm & Buffalo & 10 \\
13 & Gokul Dairy Farm, Thane & Cow & 10 \\
14 & Titwala Dairy Farm & Buffalo & 15 \\
15 & Kalyan Tabela & Buffalo & 10 \\
\hline & Total & $\mathbf{1 0 6}$ & \\
\hline
\end{tabular}

colony characters suggestive of Staphylococcus spp. were processed further for identification of the organism using standard bacteriological procedures (Edward and Ewing, 1972; Quinn, 1994; Agarwal et al., 2010). The isolates showing gram's positive spherical shape arranged in irregular grape like clusters and showing golden yellow discoloration on MSA were considered as Staphylococcus spp. and further identified by biochemical studies.

Identification: The isolates were subjected further to different identification tests recommended (Cruickshank, 1975; OIE, 2009; Agarwal et al., 2010) as described below.

Oxidase test- Standard oxidase discs (Hi Media Laboratories Ltd., Mumbai) were used to perform the test. The loopful of culture from single colony was touched on the disc. Immediate development of blue color was considered as positive test whereas in negative test no color change was observed.

Catalase test- This test was performed by taking 2-3 drops of 3 per cent $\mathrm{H}_{2} \mathrm{O}_{2}$ on clean grease-free glass slide and single colony was mixed with the help of a wire loop. Immediate production of gas bubbles was considered as positive test.

Indole test- The test was done by inoculating the organisms in tryptone broth (Himedia) and incubating at $37^{\circ} \mathrm{C}$ for $24 \mathrm{hrs}$ followed by addition of $0.2 \mathrm{~mL}$ of Kovac's reagent from side of the test tube (Hi-media). Appearance of pink colored ring was considered as positive and yellow colored ring at the interface was considered as a negative test.

Methyl-Red (MR) test- The test was performed using Methyl red (MR) broth in which pure culture was inoculated. The tubes were incubated at $37^{\circ} \mathrm{C}$ for 48 hours. Thereafter 5 drops of methyl red indicator solution was added to the test tube. Positive results were indicated by bright red color whereas yellow color indicated negative results.

Voges-Proskauer (VP) test- The test was performed using Voges-Proskauer (VP) broth in which pure culture was inoculated. The tubes were incubated for 48 hours at $37^{\circ} \mathrm{C}$. After incubation $3 \mathrm{~mL}$ of Barrit B reagent (alpha naphthol) and 1 $\mathrm{mL}$ of Barrit A $(40 \% \mathrm{KOH})$ reagent was added. The tube was exposed to atmospheric oxygen for 10-15 minutes. Positive results were indicated by pink color in 2-5 mins and negative by yellow or copper color at the surface. 
Citrate test- Simmon's citrate agar slants were inoculated from 18-24 hours old culture colony and incubated at $37^{\circ} \mathrm{C}$ and observed upto 7days. A positive reaction was observed by color change from green to blue in the slant along with growth and negative showed no color change and no growth.

Urease test- Christensen's urea agar slants were inoculated with 18-24 hours old culture and incubated at $37^{\circ} \mathrm{C}$ and observed upto 7 days. A positive reaction was observed by development of pink color in the slant and no color change of the slant in negative reaction.

\section{In vitro antimicrobial sensitivity test}

Antibiotic sensitivity test of Staphylococcus spp. was carried out by using Muller Hinton Agar (MHA) medium (Bauer et al., 1966). Antibiotic disc of imipenem (IPM $10 \mathrm{mcg}$ ), ciprofloxacin (CIP $5 \mathrm{mcg}$ ), amoxicillin/ clavulanic acid (AMC $10 \mathrm{mcg}$ ), ceftriaxone (CTR $30 \mathrm{mcg}$ ), tetracycline (TE $30 \mathrm{mcg}$ ) and amikacin (AK $30 \mathrm{mcg}$ ) from Hi media Mumbai were used. The antibiotics were graded as susceptible (S), intermediate (I) or resistant (R) based on diameter of zone of inhibition (millimetre) developed around the discs as per Clinical Laboratory Standards Institute (CLSI, 2018).

\section{Characterization of Staphylococcus aureus by Nuc PCR assay}

DNA extraction: DNA of the $S$. aureus isolates was extracted as per the method described by Wilson (2001) with some modifications.

The isolates were inoculated in BHI broth and done incubation at $37^{\circ} \mathrm{C}$ for overnight. The inoculum was then transferred to microcentrifuge tube and done the centrifugation at $12,000 \mathrm{rpm}$ for $10 \mathrm{~min}$. Discard the supernatant and pellet was mixed with $200 \mu \mathrm{L}$ of T.E. buffer and $50 \mu \mathrm{L}$ of $50 \mathrm{mg} / \mathrm{mL}$ stock solution of lysozyme was added and mixed by vortexing. This mixture was incubated at $37^{\circ} \mathrm{C}$ for $2 \mathrm{hrs}$. A $30 \mu \mathrm{L}$ of $10 \%$ SDS and $80 \mu \mathrm{L}$ of $20 \mathrm{mg} / \mathrm{mL}$ stock of proteinase $\mathrm{K}$ were then added, mixed by vortexing and incubated in water bath at $65^{\circ} \mathrm{C}$ for $1 \mathrm{hr}$. On completion of incubation, added $100 \mu \mathrm{L} 5 \mathrm{M} \mathrm{NaCl}$ and mixed thoroughly by vortexing. Then added $80 \mu \mathrm{L}$ of C-TAB/ $\mathrm{NaCl}$ solution, mixed the suspension thoroughly and incubated at $65^{\circ} \mathrm{C}$ for half an hour in dry bath. An equal volume of phenol: chloroform (1:1) was added and vortexed for 2-3 min followed by centrifugation at 12,000 $\mathrm{rpm}$ for $10 \mathrm{~min}$. Then the upper aqueous phase was transferred to a sterile microcentrifuge tube. An equal quantity of chloroform: isoamyl alcohol (24:1) was then added mixed thoroughly and done centrifugation at 12,000 rpm for $10 \mathrm{~min}$. The upper aqueous layer was transferred to a fresh micro-centrifuge tube. Then precipitation of DNA was carried out using one third volume of $7.5 \mathrm{M}$ ammonium acetate and double volume of chilled absolute ethanol. The tube containing DNA was stored at $-20^{\circ} \mathrm{C}$ for overnight. Next day the centrifugation was done at $12,000 \mathrm{rpm}$ for 15 min, the supernatant was carefully discarded leaving the DNA pellet at the bottom of the micro-centrifuged tube.The washing of pellet was done with $70 \%$ ethanol, was air dried and resuspended in $30 \mu \mathrm{L}$ of sterile nuclease free water. The samples were incubated in water bath at $65^{\circ} \mathrm{C}$ for $2 \mathrm{hrs}$. The DNA isolated as above was stored at $-20^{\circ} \mathrm{C}$ until further use.

Detection of Staphylococcus aureus using Nuc PCR: The Nuc PCR was carried out for detection of Staphylococcus aureus by using published oligonucleotide primer sequences Nuc F ( $5^{\prime}$ CGA-TTG-ATG-GTG-ATA-CGG-TT-3') and Nuc R (5'-ACG-CAA-GCC-TTG-ACG-AACTAA-AGC-3') manufactured and supplied by $\mathrm{M} / \mathrm{s}$ Bangalore Genei, Bangalore (India). This PCR assay shows an amplification product of 270 bp region of $N u c$ genetic element of Staphylococcus aureus. A PCR assay targeting of Nuc gene was employed for identification of Staphylococcus aureus during present investigation as described by Ali et al. (2014).

The PCR standardized in a reaction volume of $25 \mu \mathrm{L}$, containing 10X PCR buffer, $\mathrm{MgCl}_{2}$ (25 mM), dNTPs mix (10 mM), Primers Nuc- F 
$(10 \mathrm{pM} / \mu \mathrm{L})$ and Primer Nuc- R $(10 \mathrm{pM} / \mu \mathrm{L})$, Template DNA and Taq DNA polymerase (5 $\mathrm{U} / \mu \mathrm{L})$. The reaction was standardized in a thermal cycler (Master Cycler, Eppendorf) with initial denaturation at $94^{\circ} \mathrm{C}$ for $5 \mathrm{~min}$, followed by 35 cycles at $94^{\circ} \mathrm{C}$ for $1 \mathrm{~min}, 65^{\circ} \mathrm{C}$ for $45 \mathrm{sec}$ and $72^{\circ} \mathrm{C}$ for $45 \mathrm{sec}$. Final extension was carried out at $72^{\circ} \mathrm{C}$ for $5 \mathrm{~min}$. The amplified product was electrophoresed on $2 \%$ agarose gel stained with ethidium bromide (EtBr) and the products were visualized and documented using Automatic Computerized Gel Documentation and Analysis System (Gel Doc EZ Imager, BioRad) using UV light source. The size of PCR product was estimated with the help of Image Lab (Version 4.1) software available with the gel documentation system.

\section{RESULTS}

Isolation of Staphylococcus spp.: A total of 106 raw cattle and buffalo milk samples were processed for isolation of Staphylococcus spp. resulting in the recovery of 45 isolates $(42.45 \%)$ of Staphylococcus spp. (Table 2).

All the isolates recovered were tentatively identified as Staphylococcus spp. based on morphology, staining reaction in Gram's staining method and growth characteristics on Mannitol salt agar (MSA). Further the isolates showing gram positive cocci arranged in irregular grape like clusters (Plate 1) and colonies with golden yellow pigmentation on MSA (Plate 2) were identified as Staphylococcus aureus after results of biochemical tests. The isolates showed positive results by catalase (Plate 3), urease (Plate 4), MR (Plate 5), VP (Plate 6) and Citratetests (Plate 7) and were indole (Plate 8) and oxidase (Plate 9) negative (Table 3). The organisms were non-motile.

In vitro antimicrobial sensitivity test: Results of antimicrobial sensitivity testing showed that all 45 Staphylococcus aureus isolates (100\%) were sensitive to imipenem. Forty-one isolates (91.11\%) were sensitive to amoxicillin/ clavulanic acid. While thirty-eight isolates $(84.44 \%)$ were sensitive to ceftriaxone. 36 of 45 Staphylococcus aureus isolates (80\%) were sensitive to tetracycline, $35(77.77 \%)$ to ciprofloxacin and $32(71.11 \%)$ to amikacin. 13

Table 2. Isolation of Staphylococcus aureus from milk specimens

\begin{tabular}{llcc}
\hline Sl. No & Name of the farm & $\begin{array}{c}\text { No. of samples } \\
\text { processed for isolation }\end{array}$ & $\begin{array}{c}\text { No. of isolates } \\
\text { recovered }\end{array}$ \\
\hline 1 & Narayan Dairy Farm, Dombivli & 1 & 1 \\
2 & Durga Dairy Farm, Dombivli & 1 & 1 \\
3 & Nanda Dairy, Dombivli & 1 & 1 \\
4 & Yadav Dairy, Dombivli & 1 & 1 \\
5 & Goshala, Dombivli & 5 & None \\
6 & Kopargaon Dairy Farm & 10 & 10 \\
7 & Ambernath Dairy Farm & 20 & 14 \\
8 & Shubham Dairy Farm, Diva & 5 & None \\
9 & Shri Radha Govind Goshala, Badlapur & 5 & None \\
10 & Goshala Kalwa & 5 & None \\
11 & Local vendor, Ambernath & 7 & None \\
12 & Thane Dairy Farm & 10 & 3 \\
13 & Gokul Dairy Farm, Thane & 10 & 8 \\
14 & Titwala Dairy Farm & 15 & 6 \\
15 & Kalyan Tabela & 10 & None \\
\hline
\end{tabular}


Indian Journal of Animal Health, Special Issue, December, 2021

Molecular Detection of Staphylococcus aureus from raw milk in Mumbai

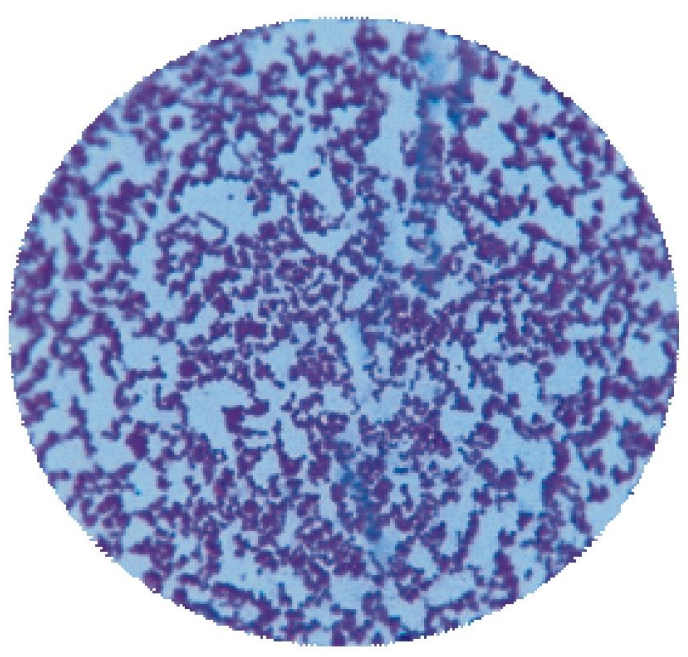

Plate 1. Gram's staining

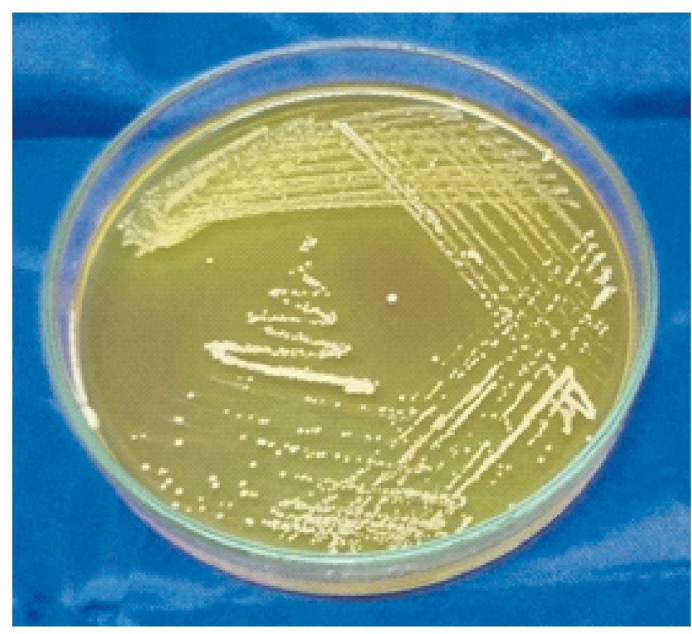

Plate 2. Colonies of Staphylococcus aureus isolated on Mannitol Salt Agar (MSA)

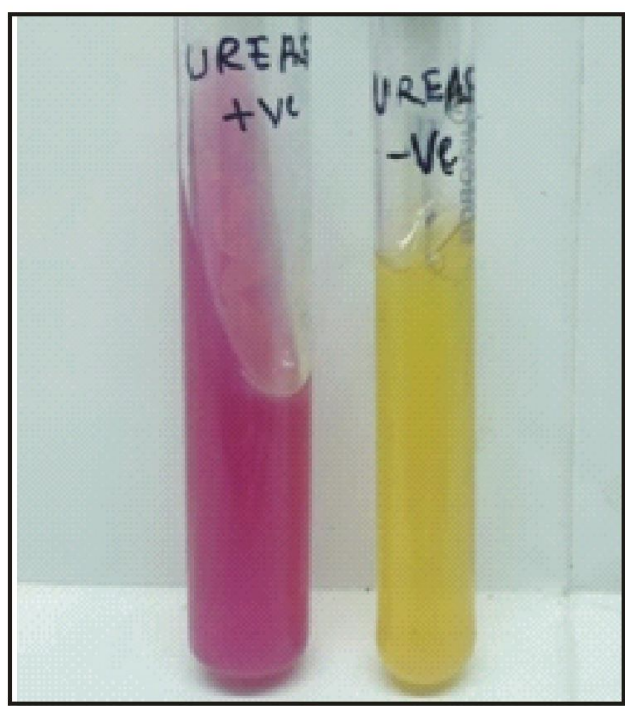

Plate 4. Urease test

\section{Plate 3. Catalase test}

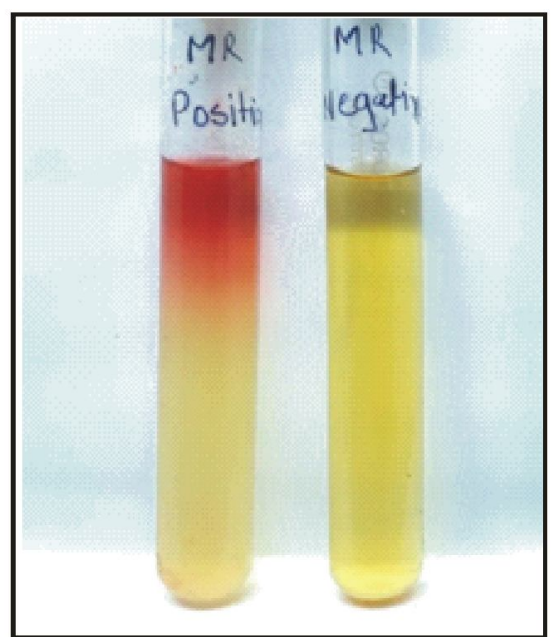

Plate 5. Methyl red test 
Indian Journal of Animal Health, Special Issue, December, 2021

Molecular Detection of Staphylococcus aureus from raw milk in Mumbai

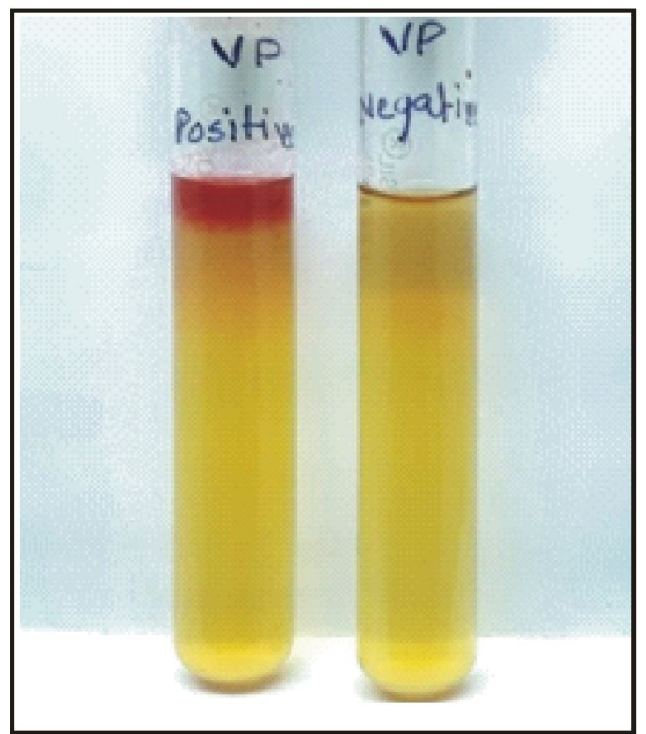

Plate 6. Voges-Proskauer test

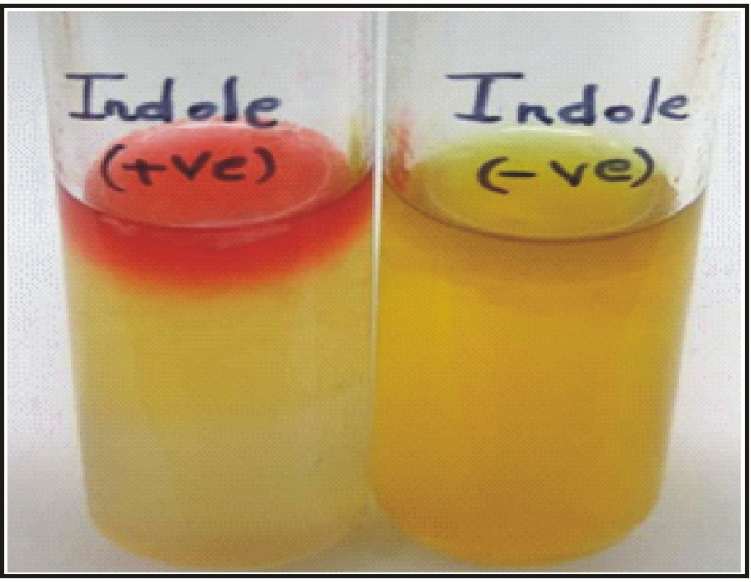

Plate 8. Indole test

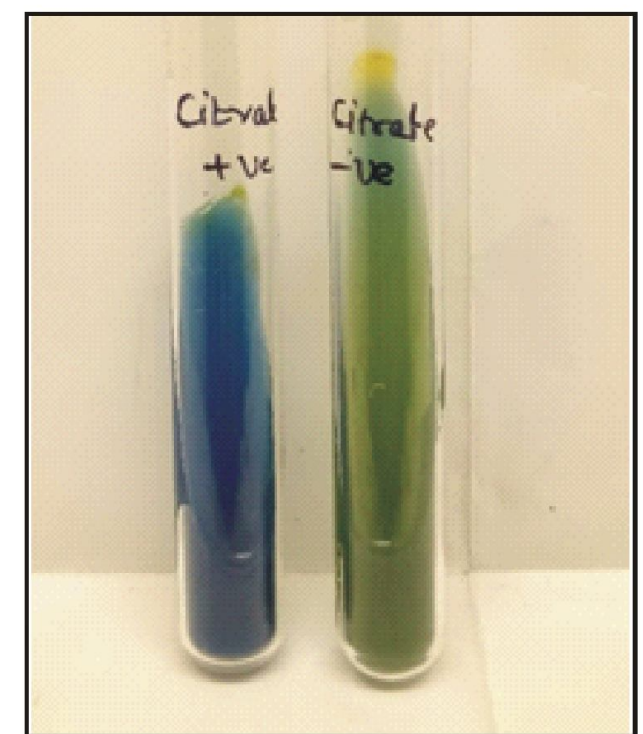

Plate 7. Citrate test

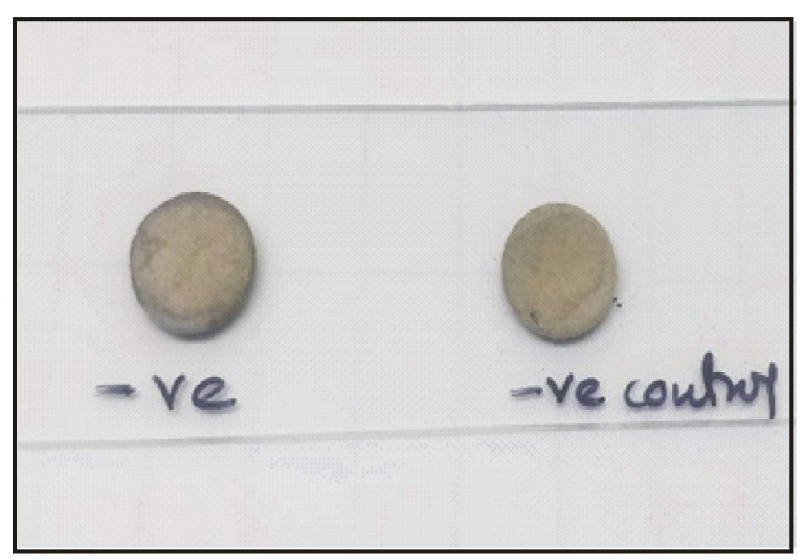

Plate 9. Oxidase test

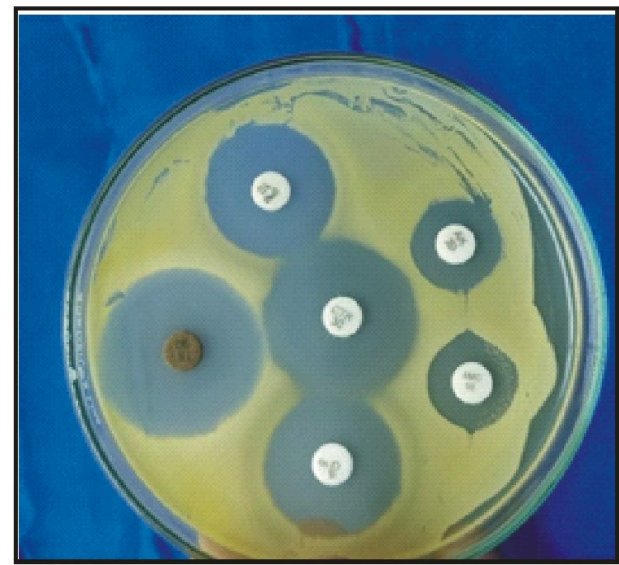

Plate 10. Antibiotic sensitivity test results 
Indian Journal of Animal Health, Special Issue, December, 2021

Molecular Detection of Staphylococcus aureus from raw milk in Mumbai

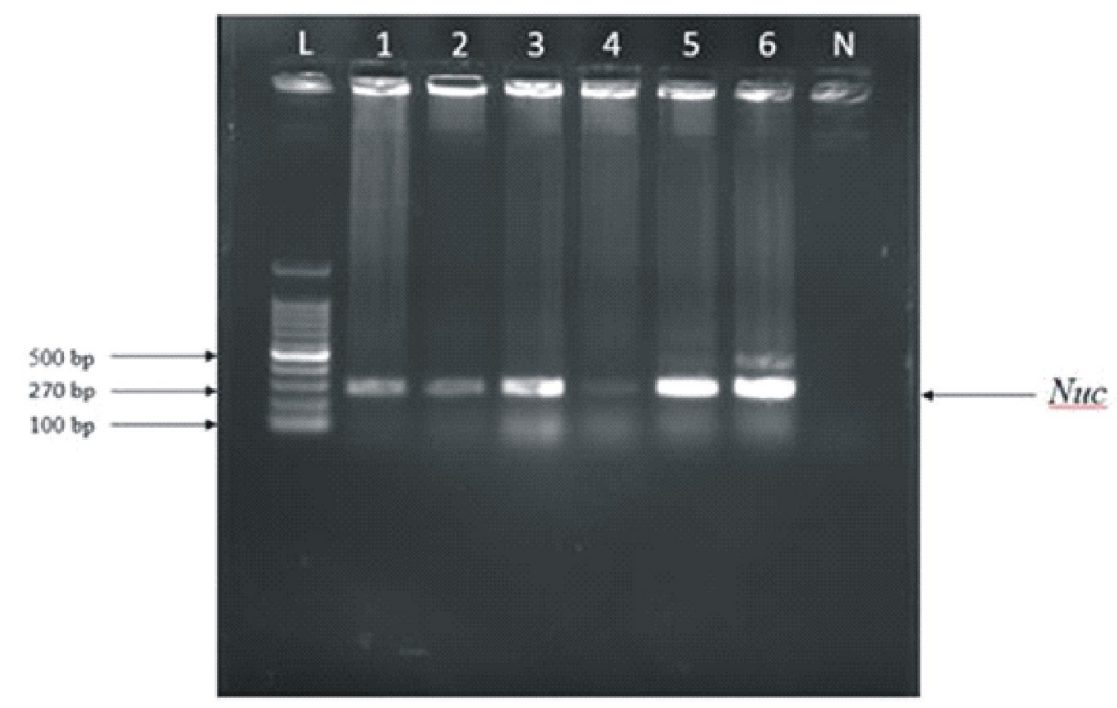

[Lane L - 100bp Ladder, 1-5 Isolates, 6- Positive control, N-Negative Control]

Plate 11: Identification of Staphylococcus aureus by Nuc PCR Assay

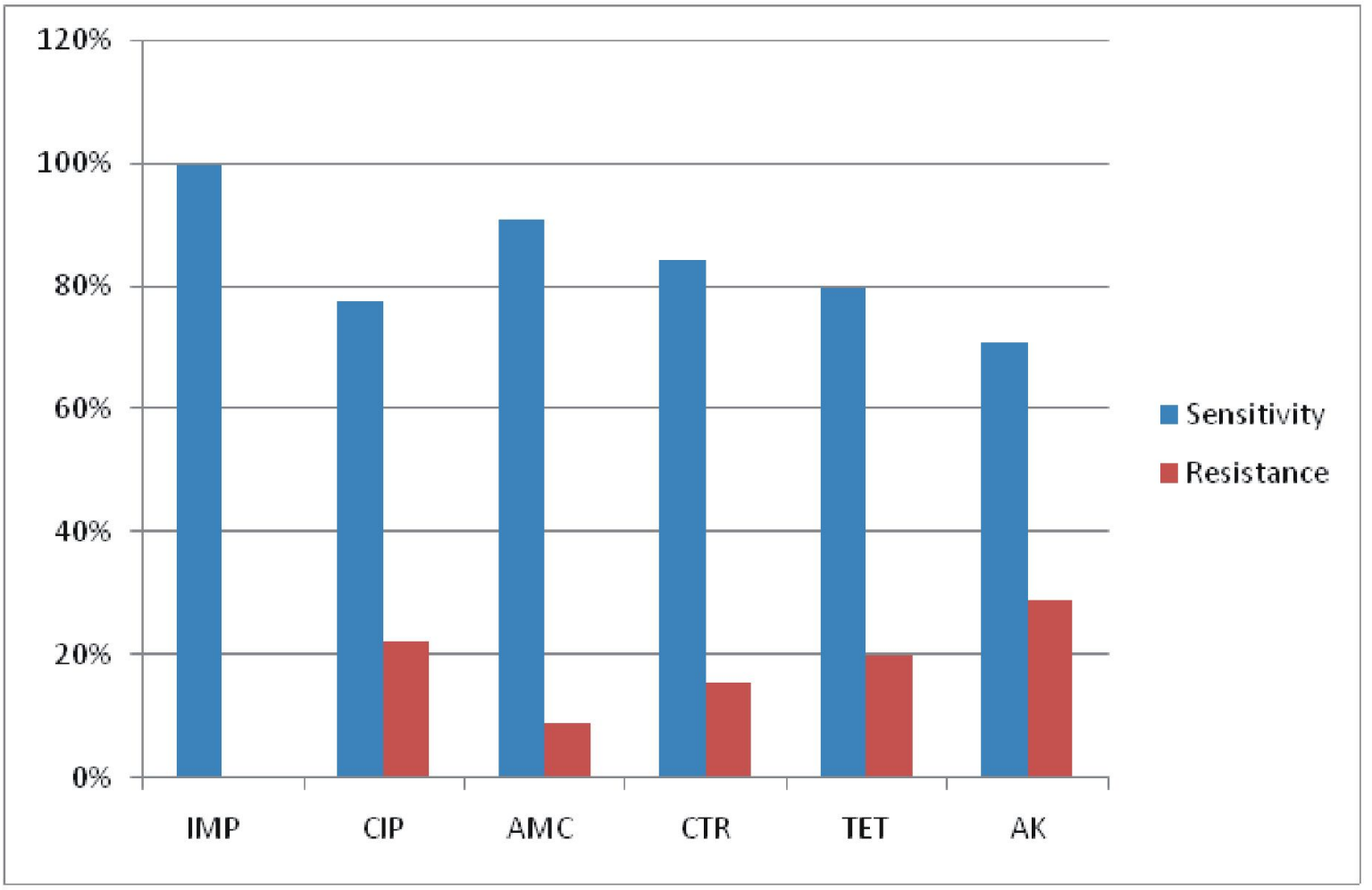

[1. IMP- Imipenem 2. CIP- Ciprofloxacin 3. AMC-Amoxicillin + clavulanic acid 4. CTR- Ceftriaxone 5. TET- Tetracycline 6. AK- Amikacin]

Graph 1. In-vitro Antimicrobial sensitivity test results of Staphylococcus aureus 
Table 3. Identification of Staphylococcus aureus isolates by biochemical tests

\begin{tabular}{clc}
\hline Sr. No. & Name of the test & Staphylococcus aureus \\
\hline 1 & Catalase test & Positive \\
2 & Urease test & Positive \\
3 & Oxidase test & Negative \\
4 & MR ( Methyl Red) & Positive \\
5 & VP ( Voges Proskaur test) & Positive \\
6 & Indole test & Negative \\
7 & Nitrate reduction test & Positive \\
8 & Citrate & Positive \\
\hline
\end{tabular}

Table 4. In-vitro antimicrobial sensitivity test results of Staphylococcus aureus

\begin{tabular}{lcccccc}
\hline Antibiotics used & IMP & CIP & AMC & CTR & TET & AK \\
\hline Resistance & None & 10 & 04 & 07 & 09 & 13 \\
& & $(22.22 \%)$ & $(8.88 \%)$ & $(15.55 \%)$ & $(20 \%)$ & $(28.88 \%)$ \\
Sensitive & 41 & 32 & 29 & 34 & 33 & 17 \\
& $(91.11 \%)$ & $(71.11 \%)$ & $(64.44 \%)$ & $(75.55 \%)$ & $(73.33 \%)$ & $(37.77 \%)$ \\
Intermediate & 04 & 03 & 12 & 04 & 03 & 15 \\
& $(8.88 \%)$ & $(6.66 \%)$ & $(26.66 \%)$ & $(8.88 \%)$ & $(6.66 \%)$ & $(33.33 \%)$ \\
Total & 45 & 45 & 45 & 45 & 45 & 45 \\
\hline
\end{tabular}

1. IMP- Imipenem, 2. CIP- Ciprofloxacin, 3. AMC- Amoxicillin + clavulanic acid, 4. CTR- Ceftriaxone, 5. TETTetracycline, 6. AK- Amikacin

$(28.88 \%)$ isolates were resistant to amikacin. $10(22.22 \%)$ were resistant to ciprofloxacin, while $09(20 \%)$ were resistant to tetracycline. 04 $(8.88 \%)$ of 33 isolates were resistant to amoxycillin/ clavulanic acid and $07(15.55 \%)$ to ceftriaxone (Plate 10, Table 4 and Graph 1) Antimicrobial sensitivity testing of Staphylococcus aureus showed that imipenem was the most effective (100\%) antibiotic followed by amoxicillin/ clavulanic acid (91.11\%), ceftriaxone $(84.44 \%)$, tetracycline (80\%), ciprofloxacin $(77.77 \%)$ and amikacin (71.11\%). The most resistant antibiotics were amikacin $(28.88 \%)$ followed by ciprofloxacin $(22.22 \%)$, tetracycline $(20 \%)$, ceftriaxone $(15.55 \%)$ and amoxycillin/ clavulanic acid $(8.88 \%)$.

Nuc PCR assay: The Nuc PCR assay using Nuc F/ Nuc R primers was employed for further confirming the identity of recovered isolates during present study. All the 45 isolates of Staphylococcus aureus were included in PCR assay. All the 45 isolates showed Nuc gene specific amplification product of $270 \mathrm{bp}$ (Plate 11) i.e all the 45 isolates carried Nuc gene. In the present study, Nuc PCR assay found to be effective in identification of Staphylococcus aureus.

\section{DISCUSSION}

The milk acts as an excellent source of many pathogenic and non pathogenic bacteria and may cause severe illness to the human. Hence such raw contaminated milk samples, if consumed by humans, might be hazardous. Also all the hygienic precautions must be followed while collecting, processing and transporting milk samples from farm to the door of consumers. The present study was planned to isolate and identify $S$. aureus from raw milk of cattle and buffalo and to characterize the isolates by $\mathrm{NucPCR}$. 
The isolation rate of Staphylococcus aureus from raw milk samples in our study was $42.45 \%$. Similar studies were conducted out by different workers on isolation of $S$. aureus from raw milk samples. Pourhassan and Taravat (2011) collected 100 raw milk samples and cultured on suitable media for isolation of organisms by conventional methods.They found $52 \%$ prevalence of Staphylococcus aureus in milk samples. Mekonnen et al. (2018) observed that $39.5 \%$ of milk samples were contaminated with Staphylococcus species in Debre Zeit, Ethiopia. Daka and Yihdego (2012) isolated seventyeight Staphylococcus aureus isolates and $48.75 \%$ isolation rate of $S$. aureus was noticed. In another study carried out in Bangladesh, out of 47 samples $12(25.53 \%)$ isolates were confirmed as S. aureus (Jahan et al., 2015). Tanzin et al. (2016) recovered 12 isolates (35.29\%) of S. aureus from 34 milk samples of cattle and buffaloes. Bano et al. (2020) processed 200 raw milk samples of cow and buffaloes in Pakistan. They found that $45 \%$ staphylococcus aureus was recovered from raw milk samples.

The present study revealed that raw milk samples have Staphylococcus aureus which can be transmitted to human through milking and consumption of milk. The higher prevalence of $S$. aureus in raw bovine milk may attribute to the lack of hygiene and sanitation in the farm or their handlers. Milk can be contaminated by Staphylococcus aureus by infection of the mammary gland, by bad hygienic habits or direct contact of human such as handling equipment of milk during or after milking, coughing, sneezing, lack of washing hands etc. Dung, mud, the milk containers used for milk is also act as the source of many pathogenic bacteria. The most important contaminant is water sample which is added in the milk at farm to increase its quantity. Long duration for reaching the milk to the consumer level increases the chance of poliferation of bacteria due to elevation of temperature of milk during transport (Hassan et al., 1978).

Results of in vitro antimicrobial sensitivity testing are in agreement with Thaker et al. (2013) who reported the sensitivity of $S$. aureus isolates towards cephalothin, co-trimoxazole, cephalexin, methicillin, gentamicin, ciprofloxacin, oxacillin, streptomycin and ampicillin. Abo-shama (2014) recovered 136 isolates of $\mathrm{S}$. aureus from 340 raw milk samples and performed antibiotic sensitivity test. These isolates showed sensitivity towards ciprofloxacin and tetracycline. Oliveira et al. (2011) isolated staphylococcus from buffalo milk samples and noticed that the organisms were sensitive to amoxycillin with clavulanic acid and resistant to ampicillin, penicillin and oxacillin.

The beta-lactam antibiotics have been widely used for treatment of Staphylococcal infections since many years. In the present study all the 45 Staphylococcus aureus isolates were sensitive to imipenem (100\%) followed by ceftriaxone $(84.44 \%)$. The tetracycline antibiotics are frequently used for treating infections caused by $S$. aureus in Iran (Eslampour et al., 2009). In the present study, the sensitivity to tetracycline was determined in $20 \%$ of the Staphylococcus aureus isolates. These findings indicate that the antibiotic sensitivity testing should be recommended in infections caused by Staphylococcus aureus.

In the present study Nuc PCR found to be effective in detecting Nuc gene from Staphylococcus aureus isolates. Similar results were recorded (Wilson et al., 1991; Brakstad et al., 1992; Sahebnasagh et al., 2014).

According to Sahebnasagh et al. (2014) compared Nuc PCR and 16S rRNA PCR for detection Staphylococcus aureus. They found that Nuc PCR is more specific than 16S rRNA PCR assay for detection of Staphylococcus aureus. Recently, findings of Nuc PCR assay were reported by Wilson et al. (1991) who used a primer set different from that used in the present study. Those investigators amplified a 450-bp segment of the gene. The studies were carried out by Brakstad et al. (1992) and it was observed that Nuc PCR has potential for the rapid diagnosis of Staphylococcus aureus infections. Akindolire et al. (2015) found that 
the $N u c$ gene is more specific in $S$. aureus isolates than 16S rRNA PCR. The Nuc PCR assay for the detection of Staphylococcus aureus was 100 per cent specific and sensitive and the assay was particularly suitable for analysis of samples shipped or stored without refrigeration (Khan et al., 1998). Further Nuc PCR assay was found to be very specific to detect Staphylococcus aureus (Kim et al., 2001; Kuzma et al., 2003; Kalorey et al., 2007).

Forty five isolates of Staphylococcus aureus were recovered from 106 raw milk samples with an isolation rate of $42.45 \%$. Imipenem and amoxicillin/ clavulanic acid were found to be more effective antibiotics while amikacin and ciprofloxacin were the least effective antibiotics against Staphylococcus aureus isolated from raw milk samples in the present study. The Nuc PCR assay was very effective in detecting Staphylococcus aureus isolates recovered from raw milk samples. Strict hygienic precautions must be followed to reduce contamination of raw milk samples at

\section{REFERENCES}

Abebe R, Hatiya H, Abera M, Megersa B and Asmare K, 2016. Bovine mastitis: prevalence, risk factors and isolation of Staphylococcus aureus in dairy herds at Hawassa milk shed, South Ethiopia. BMC Vet Res, 12(1): 1-11, doi: 10.1186/s12917-0160905-3

Abo-Shama U, 2014. Prevalence and antimicrobial susceptibility of Staphylococcus aureus isolated from cattle, buffalo, sheep and goat's raw milk in Assiut. Vet Med J, 60(141): 63-72, doi: 10.21608/ avmj.2014.170753

Agarwal A, Singh KP and Jain A, 2010. Medical significance and management of Staphylococcal biofilm. FEMS Immunol Med Microbiol, 58(2): 147-160, doi: 10.1111/j.1574-695X.2009. 00601.x

Akindolire MA, Babalola OO and Ateba CN, 2015. Detection of antibiotic resistant Staphylococcus aureus from milk: A public health implication. Int J Environ Res Public Health, 12(9): 10254-10275, doi: 10.3390/ijerph120910254

Ali R, Al-Achkar K, Al-Mariri A and Safi M, 2014. Role of polymerase chain reaction (PCR) in the farm level. Further elaborate studies are required to detect the contamination of raw milk samples at farm level and reduce its transmission to human population.

Conflict of interest: Authors have no conflict of interest in this study.

Author's contribution: VRP: Writing, original draft preparation; VDT: Writing, review and editing, conceptualization, data curation; SBM: Project administration, supervision; RSG: Visualization, investigation.

\section{ACKNOWLEDGEMENTS}

The authors are thankful to the Associate Dean, Mumbai Veterinary College, Mumbai, India for providing the necessary facilities for the research work. The authors are also thankful to advisory committee members for their technical support during research work. This research did not receive any specific grant from funding agencies in the public, commercial, or not-for-profit sectors.

detection of antibiotic-resistant Staphylococcus aureus. Egyptian J Med Hum Genet, 15(3): 293298, doi: 10.1016/j.ejmhg.2014.05.003

Bano SA, Hayat M, Samreen T, Asif M, Habiba U et al., 2020. Detection of pathogenic bacteria Staphylococcus aureus and Salmonella sp. from raw milk samples of different cities of Pakistan. Natural Sci, 12(05): 295-306, doi: 10.4236/ ns. 2020.125026

Bauer AW, Kirby WM, Sherris JC and Turck M, 1966. Antibiotic susceptibility testing by a standardized single disk method. Am J Clin Pathol, 45(4): $149-158$

Brakstad OG, Aasbakk K and Maeland JA, 1992. Detection of Staphylococcus aureus by polymerase chain reaction amplification of the nuc gene. J Clin Microbiol, 30(7): 1654-1660, doi: $10.1128 / \mathrm{jcm} .30 .7 .1654-1660.1992$

Clinical and Laboratory Standards Institute (CLSI), 2018. Performance standards for antimicrobial susceptibility testing. M100 28th edn., Wayne, PA

Cruickshank R, 1975. Medical Microbiology: A Guide 
to Diagnosis and Control of Infection. E and S Livingston Ltd. Edinburgh, London, pp 888

Daka D, Silassie SG and Yihdego D, 2012. Antibioticresistance Staphylococcus aureus isolated from cow's milk in the Hawassa area, South Ethiopia. Ann Clin Microbiol Antimicrob, 11(1): 26, doi: 10.1186/1476-0711-11-26

De Silva SASD, Kanugala KANP and Weerakkody NS, 2016. Microbiological quality of raw milk and effect on quality by implementing good management practices. Procedia Food Sci, 6: 9296, doi: 10.1016/j.profoo.2016.02.019

Edwards PR and Ewing WH, 1972. Identification of Enterobacteriaceae, 3rd edn., Burgess Publishing Co., Minneapolis, USA

Eslampour MA, Hovareshti P, Feizabadi MM, Aligholi M, Bolourchi M et al., 2009. Molecular characterization of Staphylococcus aureus isolated from bovine mastitis in Iran. Vet Microbiol, 139(1-2): 207-208, doi: 10.1016/ j.vetmic.2009.05.001

Fagundes H, Barchesi L, Nader Filho A, Ferreira LM, Oliveira CAF et al., 2010. Occurrence of Staphylococcus aureus in raw milk produced in dairy farms in Sao Paulo state, Brazil. Braz J Microbiol, 41(2): 376-380, doi: 10.1590/S1517838220100002000018

FAO, 2014. Food and Agriculture Organization of the United Nations, Available at http:/ /www.fao.org/ agriculture/dairy-gateway/milk-production [26 Feb., 2016]

Hassan ZA, Shaw EJ and Shooter RA and Caro DB, 1978. Changes in antibiotic sensitivity in strains of Staphylococcus aureus. Br Med J, 2: 536-537, doi: 10.1136/bmj.2.6136.536

Jahan M, Rahman M, Parvej MS, Chowdhury SMZH, Haque ME et al., 2015. Isolation and characterization of Staphylococcus aureus from raw cow milk in Bangladesh. J Adv Vet Anim Res, 2(1): 49-55, doi: 10.5455/javar.2015.b47

Kadariya J, Smith TC and Thapaliya D, 2014. Staphylococcus aureus and Staphylococcal foodborne disease: An ongoing challenge in public health. Biomed Res Int, 2014: 827965, doi: 10.1155/2014/827965

Kalorey DR, Shanmugam Y, Kurkure NV, Chousalkar KK, Barbuddhe SB et al., 2007. PCR-based detection of genes encoding virulence determinants in Staphylococcus aureus from bovine subclinical mastitis cases. J Vet Sci, 8(2): 151-154, doi: 10.4142/jvs.2007.8.2.151

Kerouanton A, Hennekinne JA, Letertre C, Petit L,
Chesneau O et al., 2007. Characterization of Staphylococcus aureus strains associated with food poisoning outbreaks in France. Int $\mathrm{J}$ Food Microbiol, 115(3): 369-375, doi: 10.1016/ j.ijfoodmicro.2006.10.050

Khan MA, Kim CH, Kakoma I, Morin E, Hansen RD et al., 1998. Detection of Staphylococcus aureus in milk by use of polymerase chain reaction analysis. Am J Vet Res, 59(7): 807-813

Kim CH, Khan M, Morin DE, Hurley WL, Tripathy DN et al., 2001. Optimization of the PCR for detection of Staphylococcus aureus nuc gene in bovine milk. J Dairy Sci, 84(1): 74-83, doi: 10.3168/jds.S0022-0302(01)74454-2

Kuzma K, Malinowski E, Lassa H and Klossowska A, 2003. Detection of genes for enterotoxins and toxic shock syndrome toxin-1 in Staphylococcus aureus isolated from bovine mastitis. Bull Vet Inst Pulawy, 47(2): 419-426

Lachica RVF, Hoeprich PD and Genigeorgis C, 1971. Nuclease production and lysostaphin susceptibility of Staphylococcus aureus and other catalase-positive cocci. Appl Microbiol, 21(5): 823-826

Mekonnen SA, Lam TJGM, Hoekstra J, RuttenVP, Tessema TS et al., 2018. Characterization of Staphylococcus aureus isolated from milk samples of dairy cows in small holder farms of NorthWestern Ethiopia. BMC Vet Res, 14(1): 1-8, doi: 10.1186/s12917-018-1558-1

OIE, 2004. Verocytotoxigenic Escherichia coli. In. Manual of Diagnostic Test and Vaccines for Terrestrial Animals. World Organisation for Animal Health (OIE), 2004; Available at: http:// www.oie.int

OIE, 2009. World Animal Health Information Database - Version: 1.4. Paris, France: World Organization for Animal Health. Available at http://www.oie.int In: Bovine genital Campylobacteriosis, (2009) (last modified 2013). Animal Disease Data sheet

Oliveira AA, Pinheiro Jr JW, Mota RA, Cunha ML, Lopes CA et al., 2011. Phenotype characterization of Staphylococcus species strains isolated from buffalo (Bubalus bubalis) milk. J Vet Diagn Invest, 23(6): 1208-1211, doi: 10.1177/ 1040638711428946

Pourhassan M and Taravat NA, 2011. The spatial distribution of bacteria pathogens in raw milk consumption on Malayer City, Iran. Shiraz E Med J, 12(1): 2-10

Quinn PJ, 1994. Clinical Veterinary Microbiology. Edinburgh, Mosby 
Sahebnasagh R, Saderi H and Owlia P, 2014. The Prevalence of resistance to methicillin in Staphylococcus aureus strains isolated from patients by PCR method for detection of mecA and nuc Genes. Iran J Public Health, 43(1): 84-92

Soomro AH, Arain MA, Khaskheli M and Bhutto B, 2002. Isolation of Escherichia coli from raw milk and milk products in relation to public health sold under market conditions at Tandojam, Pakistan. Pakistan J Nutr, 1(3): 151-152, doi: 10.3923/ pjn.2002.151.152

Tanzin T, Nazir KNH, Zahan MN, Parvej MS, Zesmin $\mathrm{K}$ et al., 2016. Antibiotic resistance profile of bacteria isolated from raw milk samples of cattle and buffaloes. J Adv Vet Anim Res, 3(1): 62-67, doi: 10.5455/javar.2016.c133

Thaker MN, Wang W, Spanogiannopoulos P, Waglechner N, King AM et al., 2013. Identifying producers of antibacterial compounds by screening for antibiotic resistance. Nat Biotechnol, 31(10): 922-927, doi: 10.1038/nbt.2685

Tucker PW, Hazen EE and Cotton FA, 1978. Staphylococcal nuclease reviewed: A prototypic study in contemporary enzymology. I. Isolation; physical and enzymatic properties. Mol Cell Biochem, 22(2-3): 67-77, doi: 10.1007/ BF00496235

Wilson IG, Cooper JE and Gilmour A, 1991. Detection of enterotoxigenic Staphylococcus aureus in dried skimmed milk: use of the polymerase chain reaction for amplification and detection of Staphylococcal enterotoxin genes entB and entC1 and the thermonuclease gene nuc. Appl Environ Microbiol, 57(6): 1793-1798, doi: 10.1128/ aem.57.6.1793-1798.1991

Wilson K, 2001. Preparation of genomic DNA from bacteria. Curr Protoc in Mol Biol, 56(1): 1-5, doi: 10.1002/0471142727.mb0204s56

Received-08.09.2021, Accepted-22.11.2021, Published-01.12.2021

Section Editor: Prof. M. K. Sanyal, Member, Editorial Board 